\title{
KOMUNITAS NEMATODA PADA BEBERAPA LOKASI PENANAMAN UBI KAYU DI PROVINSI LAMPUNG
}

\author{
NEMATODA COMMUNITY IN SEVERAL CASSAVA PLANTING \\ LOCATION IN LAMPUNG PROVINCE
}

\author{
D. Prayugo ${ }^{1)}$, I G. Swibawa ${ }^{2)}$, Solikhin ${ }^{2)}$ F.X. Susilo ${ }^{2)}$ \\ 1) Mahasiswa dan ${ }^{2)}$ Dosen Jurusan Agroteknologi Fakultas Pertanian Universitas Lampung \\ Jln. Prof. Dr. Soemantri Brojonegoro No. 1, Bandar Lampung 35145 \\ Email:igswibawa@yahoo.com
}

\begin{abstract}
This research that aimed to study diversity and abundance of nematode communities associated with cassava (Manihot esculenta Crantz) in Lampung Province conducted from October 2017 to February 2018. Survey of nematodes was conducted in three centers of cassava planting locations in Lampung Province, namely; district of South Lampung, Central Lampung, and East Lampung and laboratory process was carried out at the Laboratory of Plant Pests, University of Lampung. The variables of nematode community consisted of the Prominence Value (PV) of genus, number of genus, Shannon and Simpson's diversity index, abundance of all nematodes and abundance of dominant plant-parasitic nematode. The data were analyzed by analyze of variance and the mean separation was tested by Least Significant Difference (LSD) test at a $5 \%$ significance level. The results showed that 29 genus of nematodes consisting of 17 genera of plant-parasitic nematodes and 12 genera offree-living nematodes inhabits of cassava in Lampung. The dominant of plant-parasitic nematodes was Helicotylenchus, Pratylenchus, Meloidogyne, Apelenchus, and Xiphinema. Every location of cassava crops inhabited by 11-17 nematodes genera with Shannon diversity Index of 2.1 - 2.5 and Simpson's index of 0.8- 0.9. The abundance of all nematodes in each location ranged from 194.3 - 875.0 individuals / 300cc of soil, plant-parasitic nematodes 169.1-746.6 individuals / 300cc of soil, free-living nematodes 25.2 - 128.4 individuals / 300cc of soil.
\end{abstract}

Keywords: Cassava, nemtodes, Helicotylenchus, Pratylenchus.

\begin{abstract}
ABSTRAK
Penelitian ini bertujuan untuk mempelajari keragaman dan kelimpahan komunitas nematoda yang berasosiasi dengan pertanaman ubi kayu (Manihot esculenta Crantz) di Provinsi Lampung. Pengambilan sampel menggunakan metode survai dilakukan di tiga sentra pertanaman ubi kayu yang terletak di Lampung Selatan, Lampung Tengah, dan Lampung Timur. Proses laboratorium dilakukan di Laboratorium Ilmu Hama Tumbuhan Fakultas Pertanian Universitas Lampung. Penelitian dilaksanakan dari bulan Oktober 2017 sampai dengan Februari 2018. Variabel komunitas nematoda yang diamati meliputi Prominance Value (PV) genus, keragaman nematoda yang diukur dengan jumlah genus dan indeks keragaman Shannon dan indeks karagaman Simpsons, kelimpahan seluruh
\end{abstract}


nematoda dan kelimpahan genus nematoda parasit tumbuhan yang dominan. Data keragaman dan kelimpahan nematoda dianalisis ragam dan nilai tengah diuji dengan uji Beda Nyata Terkecil (BNT) pada taraf nyata 5\%. Hasil penelitian menunjukkan pada pertanaman ubi kayu di Lampung ditemukan 29 genus nematoda yang terdiri dari 17 genus nematoda parasit tumbuhan dan 12 genus nematoda hidup bebas; genus nematoda parasit tumbuhan yang dominan yaitu Helicotylenchus, Pratylenchus, Meloidogyne, Apelenchus, dan Xiphinema. pada setiap lokasi penanaman ubi kayu ditemukan 11 - 17 genus, Indeks Shannon 2,1- 2,5, dan Indeks Shimpson's 0,8 0,9. 2). Kelimpahan seluruh nematoda yang ditemukan tiap kabupaten berkisar antara 194,3 - 875,0 individu/ $300 \mathrm{cc}$ tanah, nematoda parasit tumbuhan 169,1-746,6 individu/300cc tahah, nematoda hidup bebas 25,2 128,4 individu/300cc tanah. 3). Lokasi penanaman ubi kayu mempengaruhi kelimpahan dan keragaman nematoda.

Kata kunci: Helicotylenchus, nematoda, Pratylenchus, ubi kayu

\section{PENDAHULUAN}

Provinsi Lampung merupakan salah satu daerah produsen ubi kayu terbesar di Indonesia. Pada tahun 2015, produksi produksi ubi kayu di provinsi ini $30,11 \%$ dari produksi nasional yang mencapai 8.294.913 ton dengan luas panen 325,17 ribu hektar. Produksi ubi kayu yang tinggi ini dapat terancam oleh serangan Organisme Pengganggu Tanaman (OPT). Salah satu OPT penting pada pertanaman ubi kayu adalah nematoda parasit tumbuhan.

Bridge et al. (2005) menyebutkan beberapa jenis nematoda parasit tumbuhan berasosiasi dengan pertanaman ubi kayu. Beberapa jenis nematoda yang berpotensi merusak dan menimbulkan kerugian, diantaranya adalah Meloidogyne incoginia, $M$. Javanica, Pratylenchus brachyurus, Rotylenchus renisformis, Helicotylenchus erythrinae, dan $H$. dihystera. Serangan nematoda parasit tumbuhan ini menyebabkan kerusakan pada jaringan akar sehingga fungsi akar dalam pengangkutan air dan unsur hara ke seluruh bagian tanaman lainnya menjadi terganggu.

Penelitian mengenai nematoda parasit tumbuhan pada pertanaman ubi kayu di Indonesia masih terbatas. Olehkarena itu, informasi mengenaikomunitas nematoda pada pertanaman ubi kayu di Indonesia umumnya dan di Lampung khususnya sulit didapatkan. Oleh karena itu, penelitian mengenai komunitas nematoda yang berasosiasi dengan pertanaman ubi kayu masih relevan. Penulisan artikel ini berujuan untuk mengungkapkan hasil penelitian komunitas nematoda yaitu keragaman dan kelimpahan nematoda yang berasosiasi dengan pertanaman ubi kayu dari di Lampung. Informasi mengenai komunitas nematoda ini dapat bermanfaat terutama untuk menunjang keberhasilan dalam budidaya tanaman ubi kayu.

\section{BAHAN DAN METODE}

Penelitian ini menggunakan metode survai yang berlangsung pada Juni 2017 - Februari 2018. Pengambilan sampel tanah dilakukan pada pertanaman ubi kayu milik petani pada beberapa lokasi di Lampung. Proses ekstraksi dan identifikasi nematoda dilaksanakan di Laboratorium Ilmu Hama Tumbuhan dan Laboratorium Ilmu Penyakit Tumbuhan, Fakultas Pertanian, Universitas Lampung.

Enam lokasi pertanaman ubi kayu yang 
menjadi situs pengambilan sampel tersebar di tiga kabupaten yaitu Lampung Selatan, Lampung Tengah dan Lampung Timur. Di Lampung Selatan dua situs pengambilan sampel terletak di desa Tanjung Sari kecataman Natar. Situs pertama adalah kebun milik Bapak Sahrul yang luasnya $2778 \mathrm{~m}^{2}$ yang ditanami ubi kayu klon UJ3 berumur 7 bulan, terletak pada posisi geografi 5¹6’49,59" LS, dan 105'12'152.89"BT, sedangkan situs kedua adalah kebun milik Bapak Mahyo seluas $7930 \mathrm{~m}^{2}$ yang ditanami ubi kayu klon UJ3 umur 5 bulan, terletak pada posisi geografi $5^{\circ} 17^{\prime} 43.368^{\prime \prime}$ LS dan 105²12'43.11"BT. Dua situs pengambilam sampel terdapat di Kecamatan Anak Tuha desa Bumiaji Lampung Tengah yaitu kebun ubi kayu milik Subadi seluas $8280 \mathrm{~m}^{2}$ yang ditanami ubi kayu klon UJ3 berumur 5 bulan berposisi 4º $57^{\prime} 18.95^{\prime \prime} L S$ dan $105^{\circ} 1^{\prime} 15.23$ "BT dan kebun ubi kayu milik Tarom seluas $12500 \mathrm{~m}^{2}$ yang ditanami ubikayu klon UJ3 umur 7 bulan, berposisi 457'35.19"LS dan 1050'57.46"BT. Di Lampung Timur, dua situs pengambilan sampel terletak di Kecamatan Pekalongan yaitu kebun milik Darwis seluas $16884 \mathrm{~m}^{2}$ yang ditanami ubi kayu klon UJ3 umur 12 bulan berposisi pada $5^{\circ} 04^{\prime} 84.59 \mathrm{LS}$ dan 105²'16.97"BT dan kebun milik Bapak Bibit di Sukaraja Nuban seluas $4860 \mathrm{~m}^{2}$ yang ditanamai ubi kayu klon UJ5 berumur 6 bulan pada posisi 5¹'36.40"LS dan 105²4’20.89"BT

Pada setiap lahan kebun ubi kayu ditetntukan 5 titik sampel secara sistematik yaitu 4 titik di sudut arah diagonal dan 1 titik di pusat yaitu di tengah lahan. Pada setiap titik, sampel tanah diambil menggunakan bor tanah sampai kedalam $20 \mathrm{~cm}$ pada 12 sub-titik sampel pada 2 lingkaran, 4 sub-titk sampel pada lingkaran kecil berjari-jari 3 meter dan 8 sub-titk sampel pada lingkaran besar berjari-jari 6 meter yaitu sesuai dengan metode BGBD (Susilo \& Karyanto, 2005). Sampel tanah dari 12 sub-titik sampel dikomposit kemudian diambil $1 \mathrm{~kg}$ untuk diperoses di laboratorium.

Di Laboraorium, ekstraksi nematoda dilakukan dari $300 \mathrm{cc}$ tanah menggunakan metode . penyaringan bertingkat dan sentrifugasi menggunakan larutan gula. Larutan gula dibuat dari 500 g gula dalam 11 larutan (Gafur \& Swibawa 2004). Nematoda dimatikan dengan pemanasan suspensinya pada suhu $50-70^{\circ} \mathrm{C}$, kemudian difiksasi menggunakan larutan Golden X. Nematoda dihitung mengunakan bantuan mikroskop stereo binokuler hand counter.

Preparat permanen nematoda dibuat untuk keperluan identifikasi. Pembuatan preparat nematoda permanen pada objek gelas mengunakan metode infiltrasi gliserin Seinhosrt (Hooper et al., 2005). Identifikasi 100 ekor nematoda yang diambil secara acak dilakukan sampai tingkat takson genus pada perbesaran 100 - 400 kali dengan bantuan buku identifikasi bergarbar Goodey (1963), Mai and Lyon (1975), dan Smart and Nguyen (1988). Nematoda, kemudian dikelompokkan menjadi nematoda parasit tumbuhan dan nematoda hidup bebas.

Prominence Value (PV) genus yang dihitung dengan formula (Beals 1960, dalam Norton 1978) digunakan untuk menetapkan genus nematoda yang dominan. Nilai PV dihitung dengan formula sebagai berikut: 


$$
\mathrm{PV}=\mathrm{KA} \times \sqrt{F A} ;
$$

dimana $P V=$ prominance value; $K A=$ kelimpahan absolut tiap genus dan $F A=$ frekuensi absolut yang dihitung dengan dengan formula

$\mathrm{FA}=\frac{\text { jumlah sampel mengandung genus } i}{\text { jumlah seluruh sampel }} \times 100$

Keragaman nematode dinyatakan dengan jumlah genus, Indeks Keragaman Shannon dan Indeks Keragaman Simpson's. Indeks keragaman Shannon dihitung dengan formula $\mathrm{H}^{\prime}=$-" $p i \ln p i$, dan Indeks keragaman Simpson's dihitung dengan formula Ds = 1- “(pi) ${ }^{2}$ dimana H' = Indeks Keragaman Shannon, Ds = Indeks Keragaman Simpson's; $p i=$ kelimpahan relatif dari genus kei dan $\ln =$ logaritma bilangan natural. Analisis ragam menggunakan uji $\mathrm{F}$ dan pemisahan nilai tengah menggunakan uji Beda Nyata Terkecil (BNT) pada taraf nyata $5 \%$ dilakukan terhadap kelimpahan dan keragaman nematoda menggunakan bantuan perangkat program SAS 9.1.

Tabel 1. Prominance Value (PV) genus nematoda di tiga lokasi penanaman ubi kayu di Provinsi Lampung

\begin{tabular}{|c|c|c|c|c|}
\hline \multirow{2}{*}{$\mathrm{No}$} & \multirow{2}{*}{ Genus } & \multicolumn{3}{|c|}{ Lokasi Pertanam an } \\
\hline & & $\begin{array}{l}\text { Lam pung } \\
\text { S ela tan }\end{array}$ & $\begin{array}{c}\text { L ampung } \\
\text { T imur }\end{array}$ & $\begin{array}{c}\text { Lampung } \\
\text { Tengah }\end{array}$ \\
\hline & Nematoda Parasit Tumbuhan & & $\ldots \ldots P V \ldots \ldots$ & \\
\hline 1 & Helicotylenchus & 1239.3 & 1860.9 & 529.5 \\
\hline 2 & Pratylenchus & 1851.9 & 1305.2 & 416.2 \\
\hline 3 & Meloidogyne & 852.2 & 657.8 & 290.9 \\
\hline 4 & Apelenchus & 1034.6 & 326.8 & 121.3 \\
\hline 5 & Xiphinem a & 350.2 & 227.7 & 59.6 \\
\hline 6 & Ditylenchus & 251.2 & 218 & 0.0 \\
\hline 7 & Apelenchoides & 164.2 & 286.5 & 0.0 \\
\hline 8 & Rotylenchus & 225.6 & 141.1 & 0.0 \\
\hline 9 & Radopholus & 188.8 & 107.8 & 64.2 \\
\hline 10 & Cricone me lla & 284.4 & 68.9 & 0.0 \\
\hline 11 & Longidorus & 128.4 & 187.9 & 14.3 \\
\hline 12 & Tetylenchus & 172.1 & 119.7 & 0.0 \\
\hline 13 & Tylenchulus & 187.1 & 56.8 & 0.0 \\
\hline 14 & Hoplolaimus & 0.0 & 117.3 & 71.1 \\
\hline 15 & Scutellonema & 0.0 & 174.2 & 0.0 \\
\hline 16 & Criconemoides & 110.5 & 0.0 & 0.0 \\
\hline \multirow[t]{2}{*}{17} & Tylenchus & 0.0 & 0.0 & 27 \\
\hline & Nematoda Hidup Bebas & & & \\
\hline 18 & Rhabtidis & 127.5 & 226.5 & 35.5 \\
\hline 19 & Longidorella & 171.5 & 138.3 & 11.7 \\
\hline 20 & Dorylaim inae $M G$ & 38.2 & 206.1 & 0.0 \\
\hline 21 & Mononchus & 0.0 & 240.8 & 0.0 \\
\hline 22 & Dorylaimus & 149.8 & 0.0 & 78.8 \\
\hline 23 & Iotonchus & 192.7 & 0.0 & 0.0 \\
\hline 24 & Cephalobus & 0.0 & 69.7 & 117.7 \\
\hline 25 & Brachonchulus & 174.9 & 0.0 & 0.0 \\
\hline 26 & Eucepalobus & 116.4 & 0.0 & 0.0 \\
\hline 27 & Charcarolaimus & 108.2 & 0.0 & 0.0 \\
\hline 28 & Psilencus & 68.8 & 0.0 & 0.0 \\
\hline \multirow[t]{2}{*}{29} & Pelodera & 38.1 & 15.7 & 0.0 \\
\hline & Jumlah Genus & 24 & 21 & 13 \\
\hline
\end{tabular}


Tabel 2. Jumlah genus, indeks Shannon, dan indeks Shimpson's komunitas nematode di tiga lokasi pertanaman ubi kayu di Provinsi Lampung

\begin{tabular}{lccc}
\hline \multicolumn{1}{c}{ Lokasi } & Jumlah Genus & Indeks Shannon & Indeks Simpson's \\
\hline Lampung Selatan & $17,8 \mathrm{a}$ & $2,5 \mathrm{a}$ & $0,9 \mathrm{a}$ \\
lampung Timur & $15,9 \mathrm{~b}$ & $2,5 \mathrm{a}$ & $0,9 \mathrm{a}$ \\
Lampung Tengah & $11,3 \mathrm{c}$ & $2,1 \mathrm{~b}$ & $0,8 \mathrm{~b}$ \\
\hline F hitung & $34,7^{*}$ & $5,7^{*}$ & $8,2^{*}$ \\
\hline
\end{tabular}

Keterangan : * = nyata pada taraf nyata $5 \%$; angka sekolom yang diikuti oleh huruf sama tidak berbeda nyata menurut uji BNT pada taraf nyata $5 \%$.

Tabel 3. Kelimpahan seluruh nematoda, nematoda parasit tumbuhan, dan nematoda hidup bebas di tiga lokasi pertanaman ubi kayu di Provinsi Lampung

\begin{tabular}{lccc}
\hline \multicolumn{1}{c}{ Lokasi } & Seluruh nematoda & Nematoda parasit tumbuhan & Nematoda hidup bebas \\
\hline & & $\ldots .$. indiv./300 cc tanah..... & \\
Lampung Selatan & $875,0 \mathrm{a}$ & $746,6 \mathrm{a}$ & $128,4 \mathrm{a}$ \\
Lampung Timur & $717,7 \mathrm{~b}$ & $621,7 \mathrm{a}$ & $96,0 \mathrm{~b}$ \\
Lampung Tengah & $194,3 \mathrm{c}$ & $169,1 \mathrm{~b}$ & $25,2 \mathrm{c}$ \\
\hline F hitung & $55,7^{*}$ & $59,5^{*}$ & $31,0^{*}$ \\
\hline
\end{tabular}

Keterangan : * = nyata pada taraf nyata $5 \%$; angka sekolom yang diikuti oleh huruf sama tidak berbeda nyata menurut uji BNT pada taraf nyata $5 \%$.

\section{HASIL DAN PEMBAHASAN}

Nematoda yang ditemukan pada pertanaman ubi kayu di Lampung meliputi 29 genus yang terdiri dari 17 genus nematoda parasit tumbuhan dan 12 genus nematoda hidup bebas dan jumlah genus yang ditemukan di setiap lokasi penanaman ubi kayu berbeda. Berdasarkan nilai PV empat genus nematoda parasit tumbuhan yang dominan adalah Helicotylenchus, Pratylenchus, Meloidogyne, Apelenchus dan Xiphinema (Tabel 1). Temuan ini tidak jauh berbeda dengan nematoda penghuni pertanaman ubikayu di kebun percobaan Fakultas Pertanian Unila yaitu 30 genus nematoda yang terdiri dari 16 genus nematoda parasit tumbuhan dan 14 genus nematoda hidup bebas. (Indralaksmi, 2016).Jumlah genus, Indeks Keragaman Shannon, dan Indeks Keragaman Simpson's komunitas nematoda berbeda antar lokasi penanaman ubikayu. Rata-rata jumlah genus nematoda Lampung Selatan 17,8 lebih tinggi daripada jumlah genus di Lampung Timur yaitu 15,9 dan Lampung Tengah yaitu 11,3. Indeks Keragaman Shannon nematoda di Lampung Selatan dan Lampung Timur masing-masing 2,5 dan 2,4 tidak berbeda nyata, tetapi lebih tinggi daripada indeks ini di Lampung Tengah yaitu 2,1. Indeks Keragaman Shimpson's di Lampung Selatan dan Lampung Timur masing-masing 0,9 dan 0,9 tidak berbeda nyata, tetapi lebih tinggi daripada indeks ini di Lampung Tengah yaitu 0,8 (Tabel 2). 
Tabel 4. Kelimpahan genus nematoda parasit tumbuhan yang dominan di tiga lokasi penanaman ubi kayu di Provinsi Lampung

\begin{tabular}{lccccc}
\hline \multicolumn{1}{c}{ Lokasi } & Helycotilenchus & Pratylenchus & Meloidogyne & Apelenchus & Xiphinema \\
\hline & & .....individu/300cc tanah.... & & \\
Lampung Selatan & $123,9 \mathrm{~b}$ & $185,2 \mathrm{a}$ & $88,3 \mathrm{a}$ & $103,5 \mathrm{a}$ & $35,0 \mathrm{a}$ \\
lampung Timur & $186,1 \mathrm{a}$ & $130,5 \mathrm{~b}$ & $65,8 \mathrm{~b}$ & $32,7 \mathrm{~b}$ & $24,1 \mathrm{a}$ \\
Lampung Tengah & $52,9 \mathrm{c}$ & $41,6 \mathrm{c}$ & $29,1 \mathrm{c}$ & $12,1 \mathrm{~b}$ & $6,0 \mathrm{~b}$ \\
\hline F hitung & $32,1^{*}$ & $58,5^{*}$ & $16,7^{*}$ & $10,9^{*}$ & $13,8^{*}$ \\
\hline
\end{tabular}

Keterangan : * = nyata pada taraf nyata 5\%; angka sekolom yang diikuti oleh huruf sama tidak berbeda nyata menurut uji BNT pada taraf nyata $5 \%$.

Keragaman nematoda pada pertanaman ubi kayu yang ditemukan dalam penelitian ini sedikit berbeda dengan keragaman nematoda pada pertanaman ubiakayu di Kebun Percobaan Fakultas Pertanian Unila yang secara berturutan yaitu jumlah genus $8-16$, Indeks Shannon 0,15 - 1,46 dan Indeks Shimpson's 0,20 - 0,66 (Indralaksmi, 2016).

Kelimpahan seluruh nematoda, nematoda parasit tumbuhan dan nematoda hidup bebas dipengaruhi oleh lokasi penanaman ubi kayu. Pada Tabel 3 tampak bahwa kelimpahan seluruh nematoda di Lampung Selatan, Lampung Timur, dan Lampung Tengah berturutan $875,0>717,7>194,3$ indiv./300 cc tanah. Kelimpahan nematoda parasit tumbuhan di Lampung Selatan dan Lampung Timur tidak berbeda yaitu masing-masing 746,6 dan 621,7 indiv./300cc tanah, tetapi lebih tinggi daripada kelimpahan nematoda ini di Lampung Tengah yaitu 169,1 indiv./300cc tanah. Kelimpahan nematoda hidup bebas di Lampung Selatan, Lampung Timur, dan Lampung Tengah berturutan $128,4>96,0>25,2$ indiv./300cc tanah. Kelimpahan seluruh nematoda yang ditemukan pada pertenaman ubi kayu dalam penelitian ini tidak jauh berbeda dengan kelimpahan seluruh nematoda pada pertanaman ubi kayu di Kebun Percobaan Fakultas Pertanian Universitas Lampung yaitu 873 indiv./300cc tanah (Indralaksmi, 2016).

Berdasarkan Prominance Value (PV) lima genus nematoda parasit tumbuhan terdominan yaitu Helicotylenchus, Pratylenchus, Meloidogyne, Apelenchus, dan Xiphinema. Bridge et al. (2005) menyatakan tanaman ubi kayu berasosiasi dengan banyak nematoda parasit tumbuhan diantarnya Pratylenchus, Rotylenchulus, Helicotylenchus, Scutellonema, dan Meloidogyne. Coyne (1994) menyatakan Pratylenchus dan Helicotylenchus kerap melimpah di sekitar akar tanaman ubi kayu. Pratylenchus merupakan nematoda parasit penting yang menyerang tanaman ubi kayu, dapat ditemukan di beberapa lokasi di dunia, nematoda ini mungkin akan menjadi nematoda terpenting berikutnya setelah nematoda puru akar Meloidogyne incognita. Kelimpahan nematoda parasit tumbuhan yang dominan ini dipengaruhi oleh lokasi pertanaman ubi kayu .

Nematoda parasit tumbuhan dominan yang ditemukan pada pertanaman ubi kayu di Lampung yaitu 
Helicotylenchus, Pratylenchus, Meloidogyne, Apelenchus, dan Xiphinema, merupakan nematoda parasit penting yang dapat menjadi ancaman bagi petani ubi kayu di Provinsi ini. Oleh karena itu, petani ubi kayu di Lampung harus memberi perhatian terhadap nematoda parasit tumbuhan sebelum populasinya tinggi dan menyebabkan kesusakan yang menimbulkan kerugian secara ekonomi.

Selain nematoda parasit tumbuhan, nematoda hidup bebas juga ditemukan menghuni pertanaman ubi kayu di Lampung. Secara umum nematoda hidup bebas bersifat menguntungkan bagi ekosistem pertanaian karena memiliki berbagai peran diantaranya sebagai pemakan bakteri, pemakan jamur, pemakan substrat, dan predator. Menurut Munif(2003) bahan organik seperti kompos, pupuk kandang, dan bahan organik lainnya merupakan substra bagi sumber makanan nematoda hidup bebas. Dengan demikian nematoda hidup bebas dapat meningkatkan kualitas kesehatan tanah dan kesuburan tanaman serta dapat merangsang perkembangan mikroorganisme antagonis.

Oleh karena itu, maka petani ubi kayu hendaknya selain memperhatikan populasi nematoda parasite tumbuhan agar tidak sampai mennyababkan kerugian, juga melakukan konservasi terhadap nematoda hidup bebas yang menguntungkan.

\section{KESIMPULAN}

Dari hasil penelitian ini dapat disimpulkan bahwa pada pertanaman ubi kayu di Lampung ditemukan 29 genus nematoda yang terdiri dari 17 genus nematoda parasit tumbuhan dan 12 genus nematoda hidup bebas; genus nematoda parasit tumbuhan yang dominan yaitu Helicotylenchus, Pratylenchus, Meloidogyne, Apelenchus, dan Xiphinema. pada setiap lokasi penanaman ubi kayu ditemukan 11 - 17 genus, Indeks Shannon 2,1-2,5, dan Indeks Shimpson's 0,8-0,9. 2) Kelimpahan seluruh nematoda yang ditemukan tiap kabupaten berkisar antara 194,3 - 875,0 individu/300cc tanah, nematoda parasit tumbuhan 169,1 - 746,6 individu/300cc tahah, nematoda hidup bebas 25,2 - 128,4 individu/300cc tanah. 3). Lokasi penanaman ubi kayu mempengaruhi kelimpahan dan keragaman nematoda.

\section{SANWACANA}

Dalam penelitian ini penulis mendapatkan bantuan dana penelitian dari Dr. Ir. I Gede Swibawa, M.S., dan pada kesempatan ini penulis mengucapkan banyak-banyak terimakasih

\section{DAFTAR PUSTAKA}

Bridge, J., D. L. Coyne., and C. K. Kwoseh. 2005. Nematode Parasitic of Tropical Root and Tuber Crops (Excluding Potatoes). In M. Luc, Sikora and J. Bridge (Eds.). Plant Parasite Nematodes in Subtropical and Tro pical Agricult ure. $2^{\text {nd }} \mathrm{E}$ d. CAB International. PP. 221-258.

Coyne.D.I. 1994. Nematode Pests of Cassava. African Crop Science Journal 2(4): 355-359

Gafur, A. dan I G. Swibawa. 2004. Methods in Nematodes and Soil Microbe Research for Belowground Biodiversity Assessment. Di dalam F.X Susilo, A. Gafur, M. Utomo, R. 
Everizal, S. Murwani, I G. Swibawa, (Eds.). conservation and Sustainable Management for Below-ground Biodiversityin Indonesia. Universitas Lampung.

Goodey, J. B. 1963. Soil and Freshwater Nematodes. Mathuen \& Co Ltd., London., John Wiley \&Sons, INC, New York.

Hooper, D. J., J. Hallman, \& S. A. Subbotin. 2005. Methods for Extraction, Processing and Detection of Plant and Soil Nematodes. Pp. 53-86. In: Plant Parasitic Nematodes in Subtropical and Tropical Agriculture. M. Luc, R, A, Sikora \& J. Bridge (eds). CABI Publishing, UK.

Indralaksmi, A. 2016. Pegaruh Sistem Olah Tanah dan Pengelolaan Gulma terhadap Komunitas Nematoda pada Pertanaman Ubi Kayu (Manihot esculenta Crantz) Periode Tanam Keempat di Kebun Percobaan Fakultas Pertanian Universitas Lampung. (Skripsi) Universitas Lampung. Lampung.
Mai, W. F dan H. H. Lyon. 1975. Pictorial Key to Genera of Plant Paratic Nematodes. Comstock Publishing Associates, Cornell University Press.

Munif, A. 2003. Prinsip- Prinsip Pengelolaan Nematoda Parasit Tumbuhan di Lapangan. dalam. Bahan Pelatihan. Identifikasi dan Pengelolaan Nematoda Parasit Utama Tumbuhan. 26-29 agustus 2003. Bogor.

Norton, CD. 1978. Ecology of Plant Parasitic Nematodes. John wiley and Sons, New York. Chichester, Brisbane, and Toronto.

Smart, G. C and K.B. Nguyen. 1998. Illustrated Key for the Identification of Common Nematodes in Florida. Florida.

Susilo, F.X. dan A. Karyanto. 2005. Methods for Assessment of Below-Ground Biodiversity in Indonesia. Universitas Lampung. Bandar Lampung. 